\title{
Application conditions for ester cured alkaline phenolic resin sand
}

\author{
*Ren-he Huang, Bao-ping Zhang, and Yao-ji Tang \\ Shandong University of Science and Technology, Qingdao 266510, China
}

\begin{abstract}
Five organic esters with different curing speeds: propylene carbonate (i.e. high-speed ester A); 1 , 4-butyrolactone; glycerol triacetate (i.e. medium-speed ester B); glycerol diacetate; dibasic ester (DBE) (i.e. lowspeed ester $\mathrm{C}$ ), were chosen to react with alkaline phenolic resin to analyze the application conditions of ester cured alkaline phenolic resin. The relationships between the curing performances of the resin (including pH value, gel $\mathrm{pH}$ value, gel time of resin solution, heat release rate of the curing reaction and tensile strength of the resin sand) and the amount of added organic ester and curing temperature were investigated. The results indicated the following: (1) The optimal added amount of organic ester should be $25 \mathrm{wt} . \%-30 \mathrm{wt} . \%$ of alkaline phenolic resin and it must be above 20wt.\%-50 wt.\% of the organic ester hydrolysis amount. (2) High-speed ester A (propylene carbonate) has a higher curing speed than 1, 4-butyrolactone, and they were both used as high-speed esters. Glycerol diacetate is not a high-speed ester in alkaline phenolic resin although it was used as a high-speed ester in ester cured sodium silicate sand; glycerol diacetate and glycerol triacetate can be used as medium-speed esters in alkaline phenolic resin. (3) High-speed ester A, medium-speed ester B (glycerol triacetate) and low-speed ester $\mathrm{C}$ (dibasic ester, i.e., DBE) should be used below $15^{\circ} \mathrm{C}, 35^{\circ} \mathrm{C}$ and $50^{\circ} \mathrm{C}$, respectively. High-speed ester A or lowspeed ester $\mathrm{C}$ should not be used alone but mixed with medium-speed ester $\mathrm{B}$ to improve the strength of the resin sand. (4) There should be a suitable solid content (generally $45 \mathrm{wt} . \%-65 \mathrm{wt} . \%$ of resin), alkali content (generally $10 \mathrm{wt} . \%-15 \mathrm{wt} . \%$ of resin) and viscosity of alkaline phenolic resin (generally $50-300 \mathrm{mPa} \cdot \mathrm{s}$ ) in the preparation of alkaline phenolic resin. Finally, the technique conditions of alkaline phenolic resin preparation and the application principles of organic ester were discussed.
\end{abstract}

Key words: organic ester; alkaline phenolic resin; application conditions
CLC numbers: TG221 .1
Document code: A
Article ID: 1672-6421(2016)04-231-07

$\mathrm{T}^{\mathrm{m}}$ he process of mold-making and core-making using organic ester cured alkaline phenolic resin sand is a room-temperature curable process, developed by the British Borden Company in the early $1980 \mathrm{~s}^{[1]}$. Compared with acid cured furan resin, ester cured alkaline phenolic resin has many excellent characteristics ${ }^{[2]}$. Nowadays, ester cured alkaline phenolic resin is one of the best mold binders for large and medium-sized steel castings. It is referred to as the twenty-first century mold material for foundry industry and has broad market prospects ${ }^{[2]}$.

The curing speed of ester cured alkaline phenolic resin, which mainly depends on the kinds of organic esters, is different from that of furan resin, the curing speed of which is adjusted by the total acidity or the amount of curing agent. The correct selection and use of organic

\footnotetext{
*Ren-he Huang
}

Male, born in 1965, Doctor, Professor. His research interests mainly focus on fine chemicals and founding materials.

E-mail: renhe_h@126.com

Received: 2016-04-04; Accepted: 2016-06-01 esters are particularly important when it comes to different size castings and seasons, etc. The relationship between the performances of alkaline phenolic resin and the technological condtions of its preparation has been studied and reported. In the present study, the variation of $\mathrm{pH}$ value, gel $\mathrm{pH}$ value and gel time of resin solution were studied by changing the addition amount of organic ester and the curing temperature. The tensile strength of the resin sand was influenced by the amount and composition of organic esters. This study attempts to provide the theory evidence of raw material ratio in the alkaline phenolic resin preparation and the usage principles of organic ester.

\section{Experimental procedures}

\subsection{Reagents and apparatus}

Reagents used in the present study were $37 \%$ aqueous formaldehyde, potassium hydrate, phenol, silane KH550, propylene carbonate (i.e. high-speed ester A), 1,4-butyrolactone, glycerol triacetate (i.e. medium- 
speed ester B), glycerol diacetate, dibasic ester (DBE) (i.e. lowspeed ester C) and standard Dalin sand (70-140 mesh). All the reagents mentioned above are industrial materials.

Apparatus included SLGDH-1 electrically-heated thermostatic water bath, pHs-2C pH meter, 8S-1 magnetic stirrer, SWY-B hydraulic universal resin sand strength testing machine, NDJ-1 rotary viscometer and SHY bowl-type sand mixer.

\subsection{Preparation of alkaline phenolic resin}

Proper amounts of formaldehyde and phenol were first added to the flask equipped with a thermometer, a stirrer and a reflux condenser. After the flask was heated up to $70-75{ }^{\circ} \mathrm{C}, 30 \%$ of the $50 \% \mathrm{KOH}$ aqueous solution was evenly added into the flask in a period of 1 hour and the reaction continued for another 0.5 hour at $80-85^{\circ} \mathrm{C}$. The remaining $70 \%$ of the $50 \% \mathrm{KOH}$ aqueous solution was then added into the flask when the temperature dropped to $60{ }^{\circ} \mathrm{C}$. The reaction continued for 2-6 hours at $90-$ $95{ }^{\circ} \mathrm{C}$ and stopped when the viscosity reached $150-300 \mathrm{mPa} \cdot \mathrm{s}$ $\left(25^{\circ} \mathrm{C}\right)$. Finally, $0.5 \mathrm{wt} . \%$ of saline was added after the system cooled down to room temperature.

\subsection{Measurement of $\mathrm{pH}$ value and gel time of resin solution with different curing temperatures}

A resin aqueous solution was prepared with a $1: 1$ weight ratio of water to resin. During the reaction process, different amounts of organic esters were added to the resin solution after the temperature became stable. The variation of the $\mathrm{pH}$ value as a function of time was measured, and the gel $\mathrm{pH}$ values and gel time of resin solution were recorded when the resin gelatin appeared.

\subsection{Measurement of gel $\mathrm{pH}$ value and gel time of resin solution with different amounts of organic esters}

According to the procedure of 1.3 , the variation of $\mathrm{pH}$ value with time was measured at the different curing temperatures, and the gel $\mathrm{pH}$ value and gel time of the resin solution were recorded when the resin gelatin appeared.

\subsection{Determination of tensile strength of resin sand}

Standard Dalin sand and a certain amount of organic ester were added to a bowl type sand mixer and stirred for 0.5-1 min, and then a certain amount of alkaline phenolic resin was added and stirred for 1-2 min. This mixture was poured into a mold (dog bone-shaped) for preparation of the tensile sample, and then the sample was taken out and pressed. Finally, the tensile strength was measured after $2 \mathrm{~h}, 12 \mathrm{~h}$ and $24 \mathrm{~h}$.

\section{Results and discussion}

\subsection{Effect of esters on performance of resin}

2.1.1 Effect of amount of organic ester on performance of resin The relationships between the amount of organic ester, $\mathrm{pH}$ value, gel $\mathrm{pH}$ value and gel time of resin solution are shown in Fig.1, Fig. 2 and Fig. 3. Due to the exothermic nature of alkaline phenolic resin reacting with organic esters, the temperatures of the three reaction systems increase as the reaction process proceed. Temperature variation in the three reaction systems of the different esters as a function of time are plotted in Fig.4.
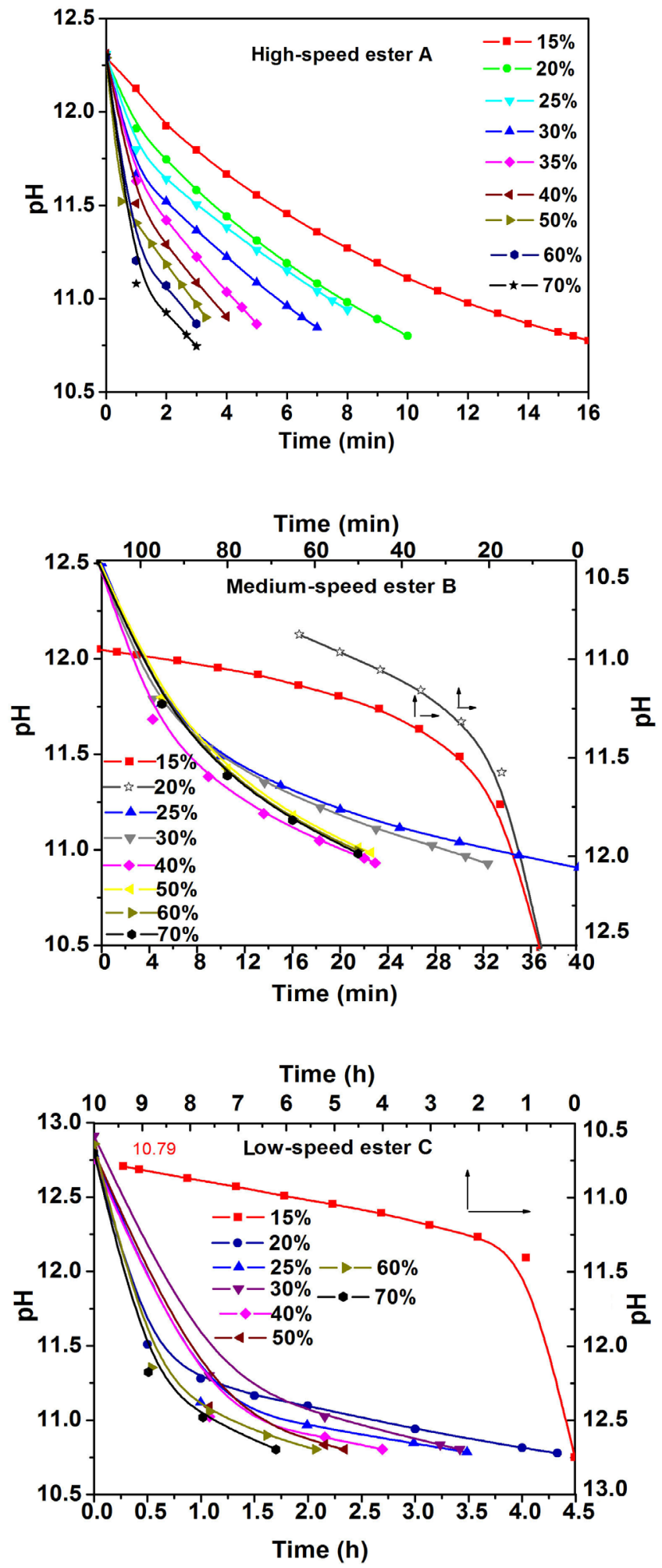

Fig. 1: Relationships between the amount of added organic ester, $\mathrm{pH}$ value, and gel time of resin solution 

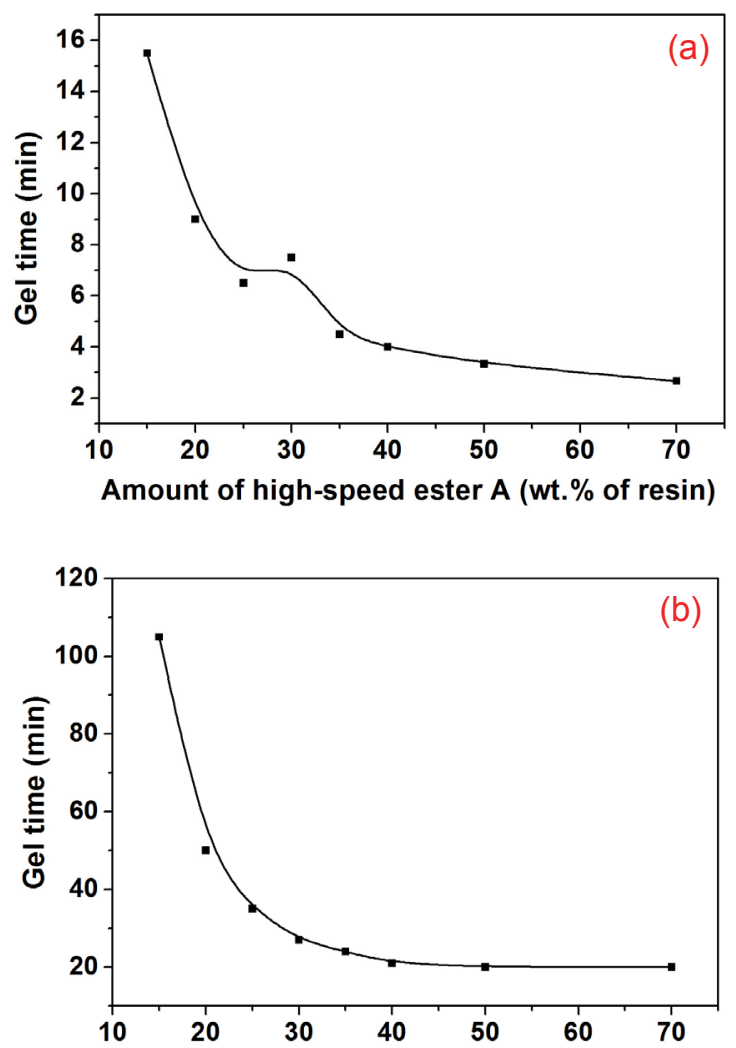

Amount of medium-speed ester B (wt.\% of resin)

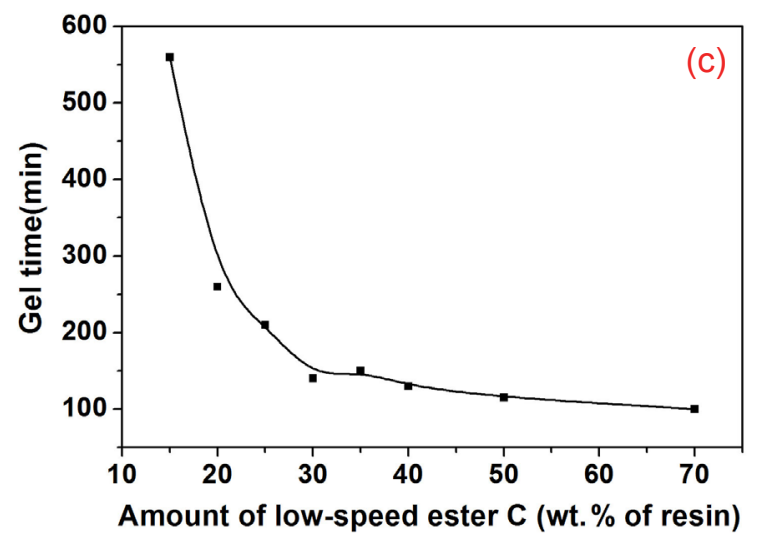

Fig. 2: Gel time of resin solution as a function of the amount of added organic esters

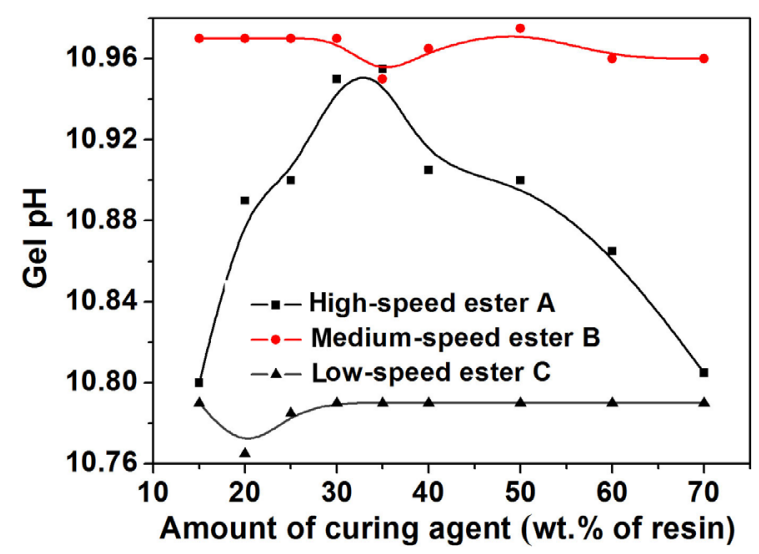

Fig. 3: Effects of the amount of added organic ester on gel $\mathrm{pH}$ value of resin solution

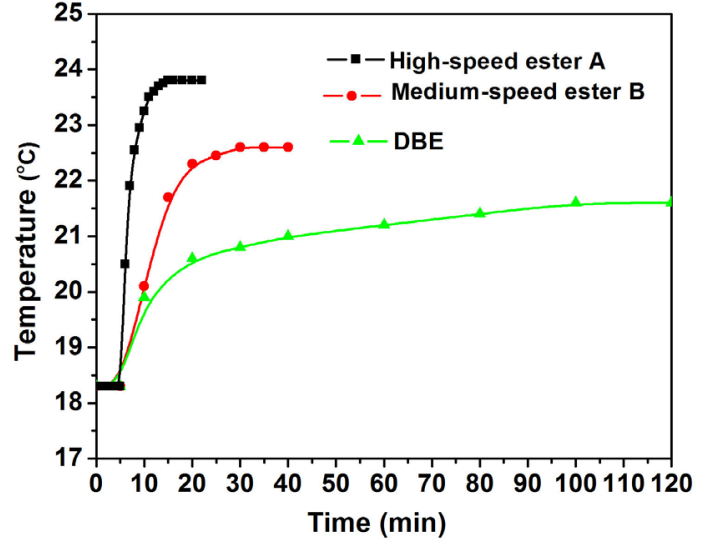

Fig. 4: Temperature variation in three reaction systems of different esters as a function of time

The $\mathrm{pH}$ value of the resin solution dropped and the gel time shortened with the increase in the amount of organic esters (curing agents), i.e., the curing speed of resin was quickened especially when the amount of curing agents was increased from $15 \mathrm{wt} . \%$ to $20 \mathrm{wt} . \%$ of the resin (see Figs.1, 2). There was no obvious change of gel $\mathrm{pH}$ value when the amount of mediumspeed ester B and low-speed ester C were higher than $25 \mathrm{wt} . \%$ of resin and high-speed ester A was higher than $35 \mathrm{wt} . \%$ of resin. The hydrolysis speed of organic ester and the curing speed of resin increased with the increase of the amount of organic ester (Fig.3).

The gelatin of the resin solution was the result of a combined action of the hydrolysis of organic ester and the curing reaction between redundant organic ester and alkaline phenolic resin ${ }^{[4]}$. The gel $\mathrm{pH}$ value of resin solution was between $10.76-10.97$, no matter which kind of organic ester was used. The change of gel $\mathrm{pH}$ value in the resin solution was very small with an increase in the amounts of medium-speed ester B and low-speed ester C. However, the effect of the amount of high-speed ester A on the gel pH value was greater (Fig. 3).

Under the same amount of curing agent (Figs.1, 2), the $\mathrm{pH}$ drop speed of resin solution was in accordance with the curing speed of resin, which mainly depended on the hydrolysis velocity of the curing agent ${ }^{[4]}$. In addition, the curing speed of resin was proportional to the heat release of the curing reaction between the resin and the curing agent (Fig. 4). The amount of organic ester addition had little effect on the curing speed. Therefore, the factor influencing the curing speed is mainly the hydrolysis speed of the organic ester which is related to the kind of organic ester. For instance, the hydrolysis speed of lactones (e.g. propylene carbonate) was faster, followed by polyhydric alcohol acetate ester (e.g. glycerol triacetate) and dibasic-acid methyl ester (e.g. dibasic ester).

\subsubsection{Effect of other organic esters on performance of resin}

In addition to high-speed ester A (i.e. propylene carbonate), medium-speed ester B (i.e. glycerol triacetate) and low-speed ester C (i.e. dibasic ester), 1,4-butyrolactone also was used as a high speed curing agent in alkaline phenolic resin. Furthermore, 
glycerol diacetate is often used as a high-speed curing agent for ester cured sodium silicate bonded sand. The $\mathrm{pH}$ value and gel time of resin solution were influenced by the five different organic esters (see Figs. 5, 6).

High-speed ester A (i.e. propylene carbonate) had a higher curing speed than 1,4-butyrolactone, and both high-speed ester A and 1,4-butyrolactone were used as high-speed curing agents in the alkaline phenolic resin. Glycerol diacetate was not a highspeed curing agent in alkaline phenolic resin although it was used as a high-speed curing agent in ester cured sodium silicate bonded sand. The reason is the different ester cured mechanisms between modified sodium silicate and alkaline phenolic resin.

There was no significant difference in the curing speed for glycerol diacetate and glycerol triacetate in alkaline phenolic resin. Glycerol diacetate also could be used as a medium-speed curing agent in alkaline phenolic resin. Therefore, it was not necessary to convert glycerol diacetate to glycerol triacetate completely during the esterification reaction between glycerol and acetic acid. Glycerol triacetate, which is sold on the market as a curing agent, also included a certain amount of glycerol diacetate.

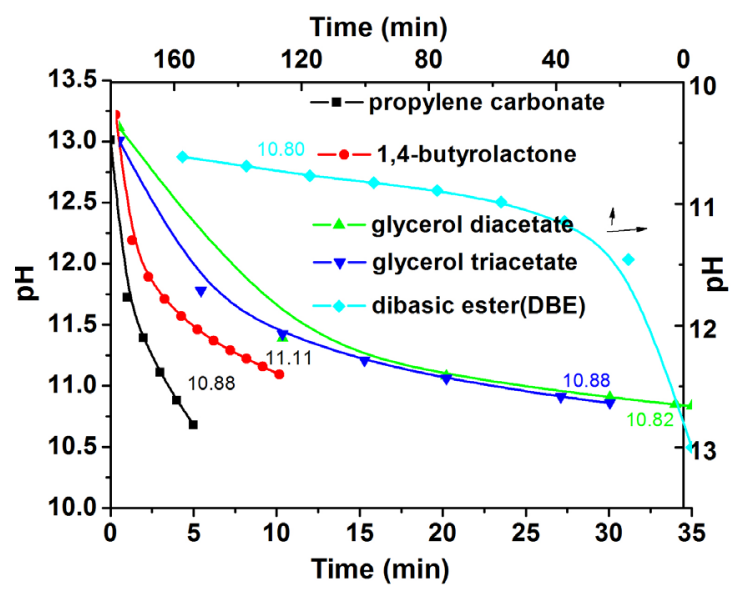

Fig. 5: $\mathrm{pH}$ variations as a function of time in resin solution reacting with different curing agents



Fig. 6: Gel time of resin solution for different curing agents

\subsubsection{Effects of organic ester on tensile strength of resin sand}

Effects of the amount of curing agent and the combined addition of organic esters on the tensile strength of resin sand are shown in Table 1 and Fig. 7, respectively.

It can also be seen from Table 1 that the tensile strength of resin sand increased with an increase in the amount of curing agent from $10 \mathrm{wt} . \%$ of resin. However, the tensile strength of resin sand was decreased when the amount of curing agent was more than $30 \mathrm{wt} . \%$ of resin. Therefore, the optimal amount of medium-speed ester B should be between 25wt.\% and 30wt.\% of resin.

On the basis of the alkali content (e.g. 12.5wt.\%) in alkaline phenolic resin and the organic ester composition, the hydrolysis amounts of organic ester for high-speed ester A, medium speed ester B and low-speed ester C were 12wt.\%-15wt.\%, $15 \mathrm{wt} . \%-17 \mathrm{wt} . \%$ and $20 \mathrm{wt} . \%-27 \mathrm{wt} . \%$ of resin, respectively. If the amount of organic ester was $25 \mathrm{wt} . \%-30 \mathrm{wt} . \%$ of resin, the residual organic ester which participated in the curing reaction accounted for $2 \mathrm{wt} . \%-18 \mathrm{wt} . \%$ in resin. If low-speed ester C is used alone, its amount should be increased in case the alkaline phenolic resin is not fully cured. In general, low-speed ester C should be mixed with medium-speed ester B.

From Fig. 7, it could be concluded that if only the highspeed ester $\mathrm{A}$ or the low-speed ester $\mathrm{C}$ was added to the sand, the tensile strengths of these resin sands were lower than those mixed with medium-speed ester B because there are 3 estergroups and 3 active $\alpha$-carbon atoms for equimolar medium-

Table 1: Effect of the amount of medium-speed ester $B$ on tensile strength of resin sand

\begin{tabular}{|c|c|c|c|}
\hline \multirow{2}{*}{$\begin{array}{c}\text { Amount of curing } \\
\text { agent* (wt. } \% \text { of resin) }\end{array}$} & \multicolumn{3}{|c|}{$\begin{array}{l}\text { Tensile strength of resin sand } \\
\text { (MPa) }\end{array}$} \\
\hline & $2 \mathrm{~h}$ & $12 \mathrm{~h}$ & $24 \mathrm{~h}$ \\
\hline $10 \%$ & 0.23 & 0.26 & 0.23 \\
\hline $20 \%$ & 0.43 & 0.49 & 0.58 \\
\hline $30 \%$ & 0.47 & 0.66 & 0.83 \\
\hline $40 \%$ & 0.27 & 0.32 & 0.61 \\
\hline
\end{tabular}

*Note: the curing agent is medium-speed ester B (i.e. glycerol triacetate)

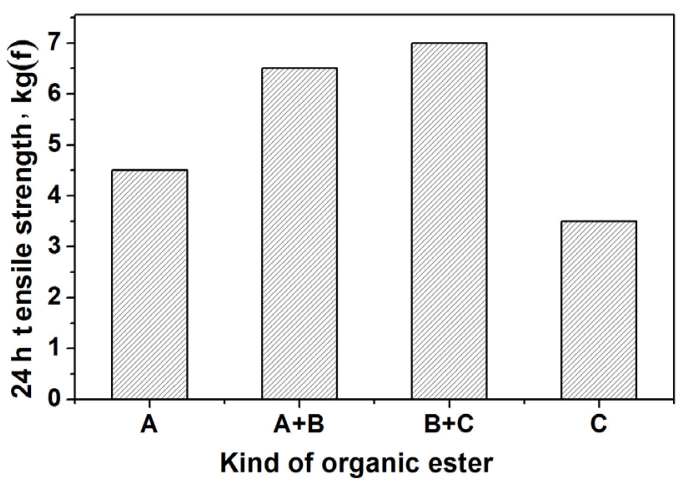

Fig. 7: Effect of different organic esters and their combined addition on tensile strength of resin sand 
speed ester $\mathrm{B}^{[5]}$. However, high-speed ester A and low-speed ester $\mathrm{C}$ had only 2 ester-groups without active $\alpha$-carbon atoms (for high-speed ester A) or with 2 active $\alpha$-carbon atoms (for low-speed ester C). The number of activity-groups in mediumspeed ester B was greater than the other organic esters ${ }^{[5]}$. Therefore, resin sand with medium-speed ester B had the highest strength.

\subsection{Temperature range of application of different organic esters}

The relationships between the curing temperature and the $\mathrm{pH}$, gel $\mathrm{pH}$, and gel time of resin solution are shown in Fig. 8 and Fig. 9.

It can be seen from Figs. 8 and 9 that no matter which kind of organic ester was used, the hydrolysis speed of organic esters and the $\mathrm{pH}$ descent speed of resin solution accelerated, and gel time was shortened with an increase in the curing temperature. The induction-time of curing reaction between residual organic ester and alkaline phenolic resin was shortened, and resin curing
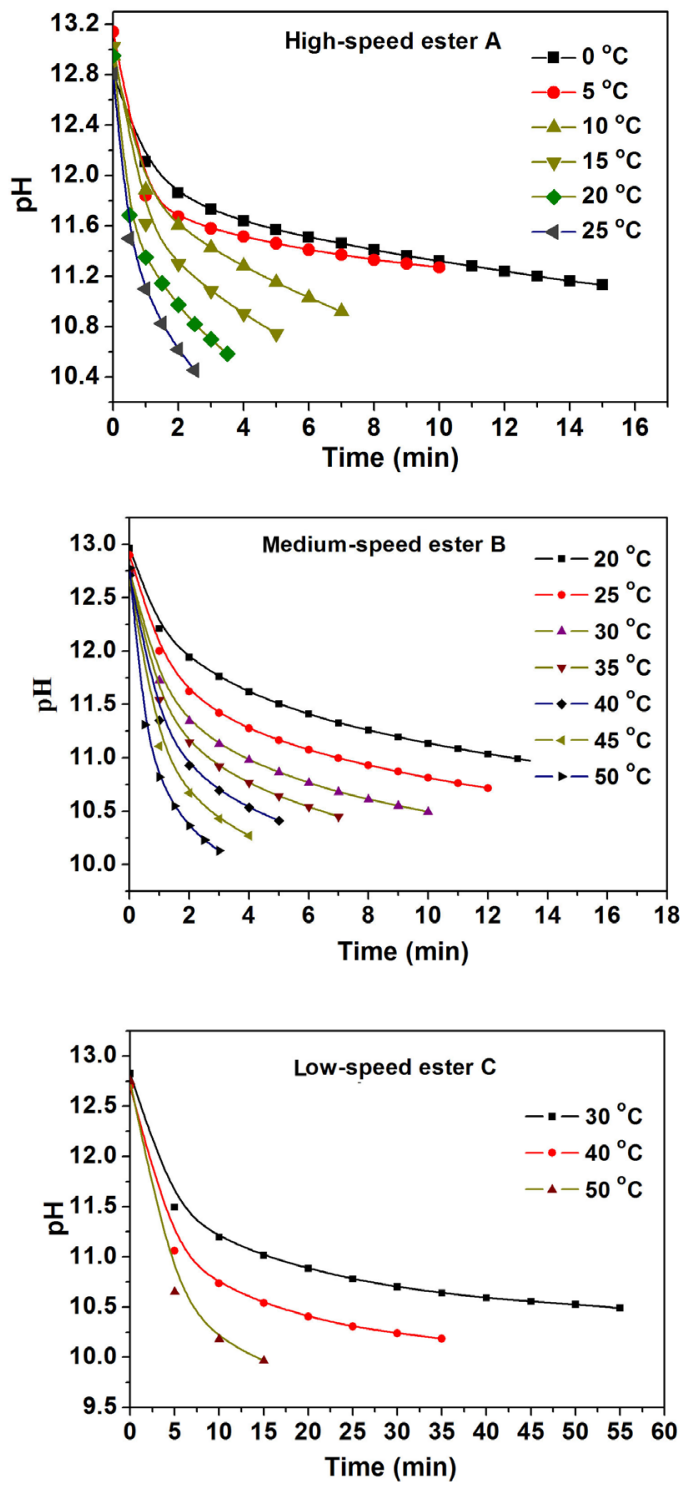

Fig. 8: $\mathrm{pH}$ variation as a function of time at different curing temperatures
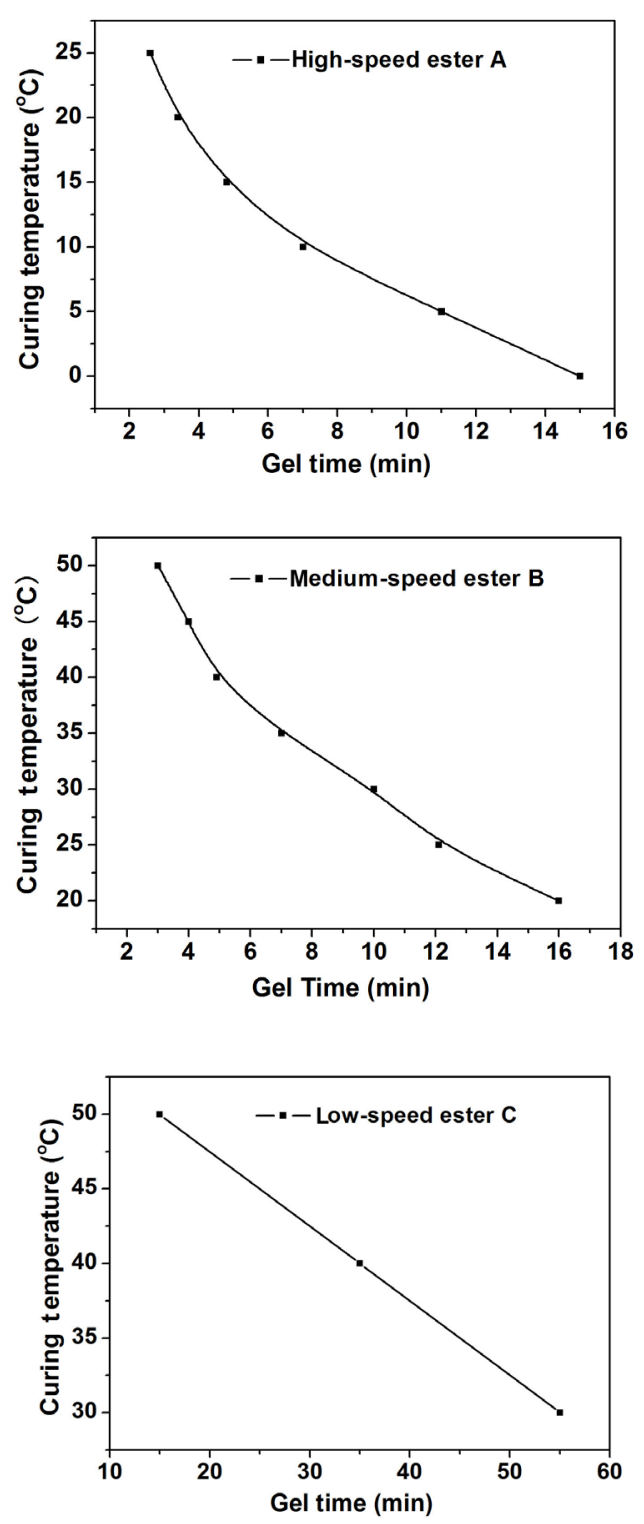

Fig.9: Effects of curing temperature on gel time of resin solution for different curing agents

rate was accelerated. For the same organic ester, gel $\mathrm{pH}$ value slightly decreased with an increase in the curing temperature. The reason was that the water solubility of gel increased and the gel $\mathrm{pH}$ value decreased with an increase in curing temperature.

From Fig. 8 and Fig. 9, it can also be shown that high-speed ester A, medium-speed ester B and low-speed ester C should be used below $15{ }^{\circ} \mathrm{C}, 35^{\circ} \mathrm{C}$ and $50{ }^{\circ} \mathrm{C}$, respectively. Generally speaking, high-speed ester A or low-speed ester $\mathrm{C}$ could not be used alone and was usually mixed with medium-speed ester B to modulate the demold time.

\subsection{Effects of other factors on curing speed of resin}

Figure 10(a) shows the effects of gel time of resin solution on the $\mathrm{pH}$ value under different dilution ratios of resin, and Fig. 10(b) shows the effect of solid content of alkaline phenolic resin on the gel $\mathrm{pH}$ and gel time of the resin solution. The 
condensation degree of resin is proportional to its viscosity, and the variations of its viscosity as a function of the gel time of resin solution are shown in Fig.11 (high-speed ester A as curing agent).

As the resin solution was diluted and the solid content was decreased, the $\mathrm{pH}$ downtrends of resin solution were basically the same (see Fig.10a). Simultaneously, the gel pH dropped and the gel time extended (see Fig.10b). Therefore, the solid content of resin solution had a certain influence on the curing speed of the resin.
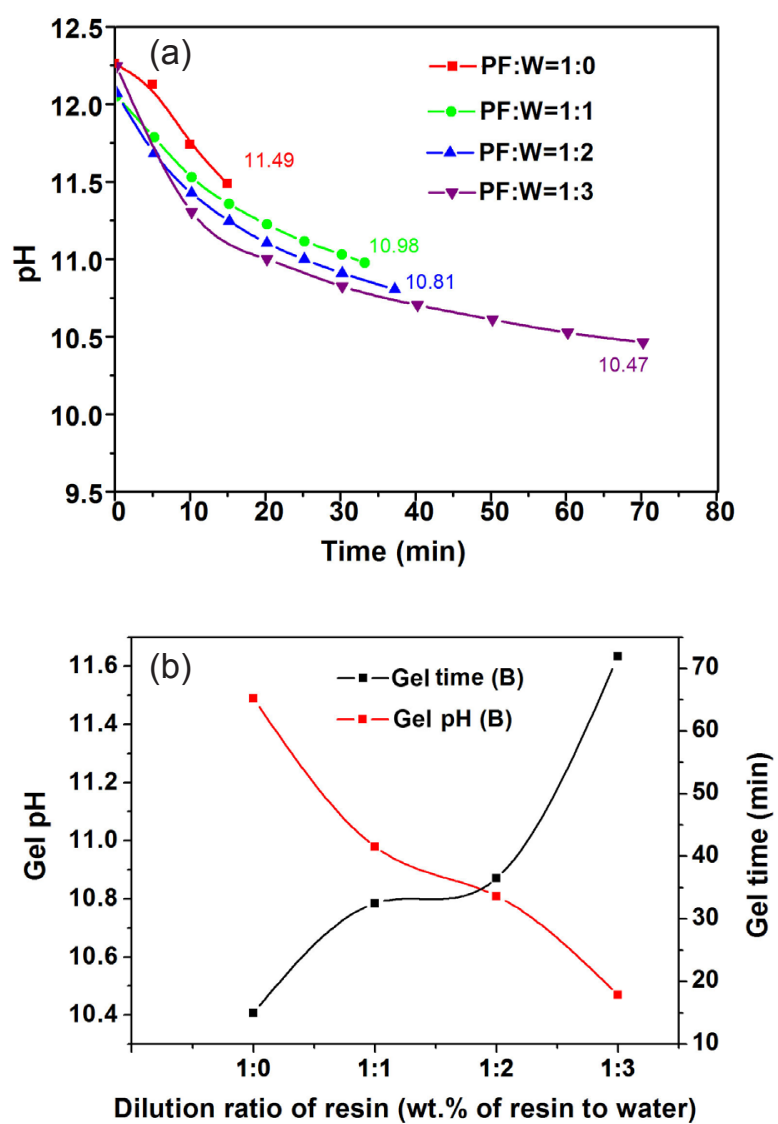

Fig.10: (a) Relationship between gel time of resin solution and $\mathrm{pH}$ under different dilution ratios of resin, and (b) effect of dilution ratios of resin on gel $\mathrm{pH}$ and gel time of resin solution



Fig. 11: Effect of viscosity on gel time of resin solution
The resin viscosity reflects the condensation degree of alkaline phenolic resin, i.e., the higher the condensation degree of the resin, the greater its viscosity, and the shorter the demold time of the resin sand. Therefore, the demold time of resin sand could also be regulated by the kind and composition of organic esters and the viscosity of resin.

\subsection{Analysis of curing agent and composition of alkaline phenolic resin}

From the curing mechanism of ester cured alkaline phenolic resin ${ }^{[4]}$, the hydrolysis of organic ester primarily happens under the condition of alkalinity, which reduces the $\mathrm{pH}$ value and the water-solubility of alkaline phenolic resin. When the $\mathrm{pH}$ value of resin is close to the gel $\mathrm{pH}$ value, residual organic ester takes part in the curing reaction of alkaline phenolic resin ${ }^{[5-7]}$. Resin gelatin appears and dehydration of the gelatin begins, which improves the strength of the resin sand. Although the curing speed accelerates with an increase in the amount of organic ester, the curing speed of alkaline phenolic resin mainly depends on the hydrolysis speed of the organic ester. The tensile strength of resin sand mainly depends on the condensation degree (i.e. viscosity) and the solid content of alkaline phenolic resin. Therefore, in order to prepare the alkaline phenolic resin to meet the requirements of curing speed and higher strength resin sand, the synthesis of alkaline phenolic resin and the use of organic esters should be considered as follows:

(1) The following questions should be taken into consideration in the preparation of alkaline phenolic resin:

Firstly, there should be a suitable solid content of alkaline phenolic resin preferably $45 \mathrm{wt} . \%-65 \mathrm{wt} . \%$ of resin, which would influence the viscosity, the curing speed of resin and the strength of resin sand.

Secondly, the alkaline phenolic resin should have a higher condensation degree, i.e., its viscosity should reach a certain value, generally $50-300 \mathrm{mPa} \cdot \mathrm{s}$. The tensile strength of resin sand, especially the early strength of resin sand, mainly depends on the condensation degree of alkaline phenolic resin (i.e. the viscosity of resin). The higher the viscosity of alkaline phenolic resin, the higher the early strength. The viscosity of alkaline phenolic resin also should not be too high, otherwise, the fluidity and the later strength of resin sand and the storage period of alkaline phenolic resin are affected.

Thirdly, there is a certain alkali content in alkaline phenolic resin. This alkali has two functions: one is to reduce the viscosity of resin and improve the fluidity of resin sand; the other is to promote the hydrolysis of organic ester and the curing of alkaline phenolic resin. Typically, a suitable alkali-content is $10 \mathrm{wt} . \%-15 \mathrm{wt} . \%$ of alkaline phenolic resin.

(2) For the curing speed requirement of resin sand, it should be considered that the lactones are the fastest organic ester in the curing speed, followed by polyhydric alcohol acetate ester and dibasic-acid methyl ester. In addition, the longer the organic acid carbon chain, the weaker its acidity. Low carbon carboxylic acid ester is preferable because there is more residual organic ester to participate in the curing reaction in the same amount of organic 
ester.

(3) The amount of curing agent influences not only the curing time of resin, but also the strength of resin sand. To ensure a higher strength resin sand, the total amount of organic ester should be above $20 \mathrm{wt} . \%-50 \mathrm{wt} . \%$ of the amount of organic ester hydrolysis which can be calculated by the alkali content in resin and the composition of organic ester. The amount of organic ester should not be excessive; otherwise, it is a disadvantage to the later strength of resin sand owing to the gradual hydrolysis of organic ester.

\section{Conclusions}

(1) Gel time shortened rapidly in the beginning with the increase of the amount of organic ester. When the amount of organic ester was more than $25 \mathrm{wt} . \%$ of alkaline phenolic resin, the downtrend of gel time was delayed. As a result, the amount of organic ester should be more than $25 \mathrm{wt} . \%$ of resin and the optimal amount should be $25 \mathrm{wt} . \%-30 \mathrm{wt} . \%$ of resin. In addition, the amount of organic ester hydrolysis can be calculated by the alkali content in alkaline phenolic resin and the organic ester composition. The actual amount of organic ester must be above $20 \mathrm{wt} . \%-50 \mathrm{wt} . \%$ of the hydrolysis amount.

(2) With the increase in the curing temperature, the gel time of resin was shortened and the curing speed of resin was increased. High-speed ester A, medium-speed ester B and low-speed ester $\mathrm{C}$ should be used below $15^{\circ} \mathrm{C}, 35^{\circ} \mathrm{C}$, and $50^{\circ} \mathrm{C}$, respectively. High-speed ester A or low-speed ester C should not be used alone and they were usually mixed with medium-speed ester $\mathrm{B}$ to improve the strength of resin sand.

(3) High-speed ester A (propylene carbonate) has a higher curing speed than 1,4-butyrolactone, and they were both used as a high-speed ester. Glycerol diacetate was not high-speed ester in alkaline phenolic resin although it was used as a highspeed ester in modified sodium silicate. Glycerol diacetate and glycerol triacetate could be used as a medium-speed ester in alkaline phenolic resin.
(4) The curing speed of organic ester mainly depended on the hydrolysis speed of the organic ester. The hydrolysis speed of lactones (e.g. propylene carbonate) was faster, followed by polyhydric alcohol acetate ester (e.g. triacetyl glycerine) and dibasic-acid methyl ester (e.g. dibasic ester).

(5) There should be a suitable solid content (generally $45 \mathrm{wt} . \%-65 \mathrm{wt} . \%$ of resin), alkali-content (generally $10 \mathrm{wt} . \%-$ $15 \mathrm{wt} . \%$ of resin) and viscosity of resin (generally 50-300 $\mathrm{mPa} \cdot \mathrm{s}$ ). The type of organic ester should be chosen according to the size of casting, the demold time, and curing speed of resin sand. In addition to the organic ester type and composition, the release time and curing time of resin sand could be adjusted by changing the viscosity of the alkaline phenolic resin.

\section{References}

[1] Westwood G W. The case for heat-cured moulding and coremaking processes. Foundry Trade Journal, 1985, 158(3308): 512-516.

[2] Wang Jin-liang, Huang Ren-he and Qu Xue-ming. Research on Reclamation Synthesizing Technique of Used Sand for Ester-cured Alkaline Phenolic Resin. Foundry, 2009, 58(2): 175-180. (In Chinese)

[3] Huang Ren-he, Chen Li-hui and Zhou Ting. Study on Antiaging and Method to Mensurate Free Aldehyde and Released Formaldehyde of Ester-solidify Alkaline Phenolic Resin. Foundry, 2012, 61(1): 57-60. (In Chinese)

[4] Huang Ren-he, Wang Yan-min and Zhang Bao-ping. Study on Curing Mechanism of Alkaline Phenolic Resin by OE. China Foundry, 2014, 11(5): 445-451.

[5] Zhao Chunling, Li Yan and Huang Naiyu. Study on Ester Cured Alkaline Phenolic Resin Binder and Cured Mechanisms. Foundry Technology, 2003, 24(1): 42-43. (In Chinese)

[6] Zhao Chunling, Huang Naiyu, Fan Zitian, et al. Mechanism of Curing Acceleration of Alkaline Phenolic Resin by Esters. J. Huazhong Univ. of Sci. \& Tech. (Nature Science Edition), 2003, 31(8): 65-67. (In Chinese)

[7] Tan Xiao-ming, Zhang Jin-chao and Peng Ai-ping. Effect of Glycerol Acetate on Acceleration of Phenolic Resin Crosslinking Reaction. Adhesion in China, 2005, 26(4): 14-16. (In Chinese) 